\title{
Excess risk of adverse pregnancy outcomes in women with porphyria: a population-based cohort study
}

\author{
Mette Christophersen Tollånes • Aasne Karine Aarsand • \\ Sverre Sandberg
}

Received: 30 April 2010 /Revised: 1 October 2010 / Accepted: 7 October 2010 /Published online: 27 October 2010

(C) The Author(s) 2010. This article is published with open access at Springerlink.com

\begin{abstract}
The porphyrias comprise a heterogeneous group of rare, primarily hereditary, metabolic diseases caused by a partial deficiency in one of the eight enzymes involved in the heme biosynthesis. Our aim was to assess whether acute or cutaneous porphyria has been associated with excess risks of adverse pregnancy outcomes. A population-based cohort study was designed by record linkage between the Norwegian Porphyria Register, covering $70 \%$ of all known porphyria patients in Norway, and the Medical Birth Registry of Norway, based on all births in Norway during 1967-2006. The risks of the adverse pregnancy outcomes preeclampsia, delivery by caesarean section, low birth weight, premature delivery, small for gestational age (SGA), perinatal death, and congenital malformations were compared between porphyric mothers and the rest of the population. The 200 mothers with porphyria had 398 singletons during the study period, whereas the 1,100,391 mothers without porphyria had 2,275,317 singletons. Firsttime mothers with active acute porphyria had an excess risk of perinatal death [adjusted odds ratio (OR) 4.9, 95\% confidence interval (CI) 1.5-16.0], as did mothers with the hereditable form of porphyria cutanea tarda (PCT) (3.0, 1.2-7.7). Sporadic PCT was associated with an excess risk of SGA [adjusted relative risk (RR) 2.0, 1.2-3.4], and for first-time mothers, low birth weight (adjusted OR 3.4, 1.2-
\end{abstract}

Communicated by: Georg Hoffmann

Competing interest: None declared.

M. C. Tollånes $(\bowtie) \cdot$ A. K. Aarsand $\cdot$ S. Sandberg

The Norwegian Porphyria Centre (NAPOS), Laboratory of

Clinical Biochemistry, Haukeland University Hospital,

NO-5021 Bergen, Norway

e-mail: mette.tollanes@helse-bergen.no
10.0) and premature delivery $(3.5,1.2-10.5)$ in addition. The findings suggest women with porphyria should be monitored closely during pregnancy.

$\begin{array}{ll}\text { Abbreviations } \\ \text { ALA } & \text { delta aminolevulinic acid } \\ \text { ALAD } & \text { delta aminolevulinic acid dehydratase } \\ \text { AIP } & \text { acute intermittent porphyria } \\ \text { CEP } & \text { congenital erythropoietic porphyria } \\ \text { PBG } & \text { porphobilinogen } \\ \text { PCT } & \text { porphyria cutanea tarda } \\ \text { EPP } & \text { erythropoietic protoporphyria } \\ \text { HCP } & \text { hereditary coproporphyria } \\ \text { VP } & \text { variegate porphyria } \\ \text { SGA } & \text { small for gestational age } \\ \text { NAPOS } & \text { the Norwegian Porphyria Centre } \\ \text { MBRN } & \text { the Medical Birth Registry of Norway } \\ \text { OR } & \text { odds ratio } \\ \text { RR } & \text { relative risk } \\ \text { BMI } & \text { body mass index }\end{array}$

\section{Introduction}

The porphyrias comprise a heterogeneous group of rare, mainly hereditary, diseases caused by partial deficiencies in one of the eight enzymes involved in the heme biosynthesis (Puy et al. 2010). Symptoms of disease can present as acute attacks of abdominal pain and neuropsychiatric symptoms [delta aminolevulinic acid dehydratase (ALAD) deficiency and acute intermittent porphyria (AIP)], cutaneous symptoms [congenital erythropoietic porphyria (CEP), porphyria cutanea tarda (PCT), and erythropoietic protoporphyria 
(EPP)] or both (hereditary coproporphyria (HCP) and variegate porphyria (VP)). Acute attacks are triggered by various factors, such as endocrine changes, physical or emotional stress, alcohol consumption, smoking, and a wide array of drugs. Cutaneous symptoms consist of blistering and fragile skin on sun-exposed areas (CEP, PCT, HCP, VP) and photosensitization (EPP). With the exception of PCT, which also occurs in a sporadic, nonhereditary form, most porphyrias are inherited in an autosomal dominant fashion with low clinical penetrance.

As with many other rare diseases, little is known about the porphyrias and reproduction. Pregnancy has been reported to exacerbate or improve cutaneous symptoms in women with PCT (Baxi et al. 1983; Loret de Mola et al. 1996; Aziz Ibrahim and Esen 2004) and EPP (Bewley et al. 1998; Jacquemyn 2003; Madu and Whittaker 2006), and women with AIP sometimes have their first acute attack during pregnancy (Engelhardt et al. 2004; Cappell 2008). However, how porphyria can affect pregnancy outcomes has seldom been investigated, and the body of evidence only consists of case reports and small case series. Acute porphyrias have been implied to be risk factors for low birth weight, growth retardation, premature delivery, spontaneous abortion, and perinatal death (Brodie et al. 1977; Olund 1988; Kanaan et al. 1989; Milo et al. 1989; Wenger et al. 1998; Aggarwal et al. 2002; Andersson et al. 2003; Muralidhar et al. 2006; Cappell 2008), whereas PCT has been suggested to increase the risk of preeclampsia (Loret de Mola et al. 1996; Aziz Ibrahim and Esen 2004).

The aim of this study was to assess whether cutaneous or acute porphyria has been associated with excess risks of adverse pregnancy outcomes, specifically preeclampsia, delivery by caesarean section, low birth weight, premature delivery, small for gestational age (SGA) infants, perinatal death, and congenital malformations. Two national registries, the Norwegian Porphyria Register and the Medical Birth Registry of Norway (MBRN), provided the basis of a large-scale population-based cohort study to address these issues.

\section{Methods}

The Norwegian Porphyria Centre (NAPOS) has a national responsibility for diagnosing porphyric disease in Norway. All Norwegian porphyria patients, both with active disease and those presymptomatically examined (latent porphyria) are invited to participate in the Norwegian Porphyria Register, established in 2002 and based on written consent. Approximately $70 \%$ of all known porphyria patients in Norway participate by filling in a disease-specific questionnaire at the time of diagnosis and a follow-up questionnaire every second year thereafter. In addition, laboratory data of porphyrin analyses are included whenever routine samples are sent for analyses. The register contains information on diagnosis, biochemical characteristics, symptoms, treatment, daily life activities, and quality of life. By September 2009, 604 patients were registered: 335 females and 269 males. Established in 1967, the MBRN is based on compulsory notification of all live births and stillbirths in the country from 16 weeks of gestation and from 2001 from 12 weeks of gestation (Irgens 2000). The MBRN comprises demographic data on parents and child, maternal health before and during index pregnancy, interventions and complications during pregnancy and delivery, and the newborns' condition. The MBRN is routinely linked to the Central Population Registry to obtain data on death dates.

During the autumn of 2009, all women older than 18 years in the Norwegian Porphyria Register were sent a letter of information about our study. Two women refrained from participation. Data on diagnosis, biochemical characteristics (highest recorded urinary excretion of ALA and PBG in women with acute porphyrias (AIP, HCP, or PV), highest recorded total urine porphyrins in women with $\mathrm{PCT}$, and highest recorded erythrocyte protoporphyrins in women with EPP), disease status, and lifestyle parameters of 318 women with porphyria were obtained. Enabled by each woman's unique national identification number, these data were linked with records of deliveries at the MBRN. Data on year of delivery, maternal age, parity, preeclampsia, caesarean section, birth weight, gestational age, perinatal death (stillbirth at gestational age $\geq 16$ weeks, or death during the first 7 days of life), and congenital malformations (any and serious, as defined by the MBRN) were obtained from the MBRN. SGA, a proxy for in utero growth retardation, was defined as birth weight below the tenth percentile for actual gestational age (Skjaerven and Bakketeig 1989). Multiple pregnancies were excluded. The study population ultimately consisted of the 2,275,715 singletons born between 1967 and 2006 by 1,100,591 unique mothers. The exposed group consisted of the 398 singletons born by the 200 mothers with porphyria. Biochemical data standardized by urine creatinine values were available for 180 of these mothers.

In agreement with others (De Siervi et al. 1999; Kauppinen and von und zu Fraunberg 2002), the 90 women with acute porphyria (AIP, HCP, or VP) were categorized as having active or latent disease depending on whether or not they had reported symptoms that could be attributed to acute porphyria to the Norwegian Porphyria Register. Deliveries by women with active and latent disease were then analyzed separately. Deliveries by women with PCT were stratified according to whether a genetic cause of the disease had been established by demonstration of a mutation in the uroporphyrinogen decarboxylase gene 
(familial PCT) or not (sporadic PCT). The 22 deliveries by mothers with unknown PCT status were excluded from further analyses. Because of the small number of deliveries in the EPP group, they were also excluded from further analyses. No patients with CEP or ALAD deficiency were registered in the Norwegian Porphyria Register.

The Mann-Whitney $U$ test was used to compare biochemical data. Risks of adverse pregnancy outcomes were compared between the porphyric mothers and the rest of the population using $2 \times 2$ tables and logistic regression models (STATA Intercooled, version 9). For rare outcomes, the effect-estimate odds ratio (OR) was considered a sufficiently good approximation of the relative risk (RR). For the SGA outcome, however, log binominal regression models were used to estimate the RRs directly. Maternal age, parity, and year of delivery were considered possible confounders and hence adjusted for as categorical variables in the regression models (maternal age: $<25,25-34,35+$ years, parity: nulliparous/ multiparous, year of delivery: 1967-1976, 1977-1986, 1987-1996, 1997-2006). Two-sided $p$ values $<0.05$ were considered statistically significant. ORs and RRs are presented with $95 \%$ confidence intervals (CI). We checked for statistically significant interactions between exposure and each of the possible confounders; none were found. As subsequent deliveries by the same mother are not independent incidents, robust variances, CIs and $p$ values were estimated using the "cluster" function in STATA, and subanalyses stratified according to parity were also performed.

\section{Results}

The 200 mothers with porphyria had 398 singleton deliveries between 1967 and 2006 (Table 1). Compared with controls, they were in general younger, had a higher parity, and a higher proportion of deliveries during the earlier parts of the study period.

Women with active acute disease had higher recorded urinary excretion of ALA $(p=0.013)$ and PBG $(p=0.001)$ compared with women with latent acute disease (Table 2). There were no statistically significant differences between the highest recorded urinary excretions of total porphyrins among the subgroups with PCT. All women with PCT had a high urinary excretion of uro- and hepta porphyrins compared with coproporhyrins.

Among the 136 deliveries in the group with active acute porphyria, the estimate of excess risk of perinatal death did not reach statistical significance (Table 3 ). However, when the analyses were restricted to firstborn children only, an almost fivefold increased risk of perinatal death was observed [adjusted OR 4.9 (1.5-16.0)]. Among the 95 deliveries in the familial PCT group, a threefold increased risk of perinatal death was observed (Table 4). All the women experiencing perinatal loss belonged to different families and carried private mutations (three in the hydroxymethylbilane synthase gene, one in the protoporphyrinogen oxidase gene, and four in the uroporphyrinogen decarboxylase gene), as is common in the porphyrias.

Among the 68 deliveries in the sporadic PCT group, a two-fold increased risk of SGA was observed (Table 4). When analyses were restricted to firstborn children only, there were also increased risks of low birth weight [adjusted OR $3.4(1.2-10.0)$ ] and premature delivery [adjusted OR $3.5(1.2-10.5)]$. No case of preeclampsia was observed among mothers with sporadic PCT (Table 4). For mothers with familial PCT, a nonsignificant estimate of a twofold increased risk of preeclampsia was observed. Restricting analyses to firstborn children only did not alter this estimate.

\section{Discussion}

First-time mothers with active acute porphyria and mothers with familial PCT had excess risks of experiencing perinatal loss. Mothers with sporadic PCT had an excess risk of giving birth to SGA infants, and first-time mothers with sporadic PCT also had increased risks of low birth weight infants and premature delivery. For the remainder, and thus the majority of the adverse pregnancy outcomes studied, no excess risks were observed for porphyric mothers.

Pregnancy outcomes in porphyric women have previously not been examined in large-scale population-based cohort studies, and the application of this design is the greatest strength of this study. Reporting to the MBRN is compulsory, and the degree of completeness is very high (Irgens 2000). Several variables have been validated and found to be satisfactory (Baghestan et al. 2007; Kubon et al. 2007), indicating reliable data. One weakness of the study, however, is the misclassification of an unknown number of mothers with porphyria as controls. Porphyric mothers not participating in the Norwegian Porphyria Register, as well as undiagnosed mothers, were included in the control group. This was probably particularly relevant for deliveries in the most recent time periods, during which mothers might not have been diagnosed by the time of data collection in 2009, especially mothers with PCT, which usually occurs after childbearing age. However, as this misclassification would have been independent of the outcomes registered, it would have caused effect estimates to be biased toward the null value. The possibility of residual confounding is another potential weakness. In particular, important lifestyle parameters are lacking in the MBRN. Maternal educational level, a useful proxy of social 
Table 1 Singleton deliveries by women with porphyria and the rest of the population (controls). Norway, 1967-2006

\begin{tabular}{|c|c|c|c|c|c|c|}
\hline & $\begin{array}{l}\text { Acute intermittent } \\
\text { porphyria (AIP) }\end{array}$ & $\begin{array}{l}\text { Hereditary } \\
\text { coproporphyria (HCP) }\end{array}$ & $\begin{array}{l}\text { Variegate } \\
\text { porphyria (VP) }\end{array}$ & $\begin{array}{l}\text { Erythropoietic } \\
\text { protoporphyria (EPP) }\end{array}$ & $\begin{array}{l}\text { Porphyria cutanea } \\
\text { tarda (PCT) }\end{array}$ & Controls \\
\hline No. singleton deliveries & 175 & 2 & 21 & 15 & 185 & $2,275,317$ \\
\hline No. mothers & 80 & 1 & 9 & 8 & 102 & $1,100,391$ \\
\hline \multicolumn{7}{|c|}{ Characteristics of population } \\
\hline \multicolumn{7}{|l|}{ Maternal age in years $(\%)$} \\
\hline$<25$ & 36.6 & 50.0 & 42.9 & 6.7 & 35.1 & 33.0 \\
\hline $25-34$ & 57.7 & 50.0 & 47.6 & 86.7 & 60.5 & 57.0 \\
\hline $35+$ & 5.7 & 0.0 & 9.5 & 6.7 & 4.3 & 10.0 \\
\hline \multicolumn{7}{|l|}{ Parity $(\%)$} \\
\hline Nulliparous & 39.4 & 50.0 & 33.3 & 46.7 & 38.4 & 41.3 \\
\hline Multiparous & 60.6 & 50.0 & 66.7 & 53.3 & 61.6 & 58.7 \\
\hline \multicolumn{7}{|l|}{ Year of delivery $(\%)$} \\
\hline $1967-1976$ & 26.3 & 0 & 47.6 & 26.7 & 61.1 & 27.4 \\
\hline 1977-1986 & 28.0 & 50 & 38.1 & 26.7 & 21.1 & 22.2 \\
\hline 1987-1996 & 29.1 & 50 & 9.5 & 20.0 & 10.8 & 25.6 \\
\hline $1997-2006$ & 16.6 & 0 & 4.8 & 26.7 & 7.0 & 24.9 \\
\hline \multicolumn{7}{|c|}{ No. adverse pregnancy outcomes } \\
\hline Pre-eclampsia/eclampsia & 2 & 0 & 1 & 0 & 5 & 66,211 \\
\hline Caesarean section & 9 & 0 & 1 & 3 & 10 & 207,947 \\
\hline Birth weight $<2500 \mathrm{~g}$ & 3 & 0 & 2 & 3 & 13 & 95,500 \\
\hline Missing data & & & & & & 5335 \\
\hline Gestational age $<37$ weeks & 9 & 0 & 2 & 2 & 12 & 124,959 \\
\hline Missing data & 11 & & & & 13 & 121,552 \\
\hline Small for gestational age & 20 & 0 & 2 & 4 & 31 & 232,051 \\
\hline Missing data & 11 & & & & 13 & 126,028 \\
\hline Perinatal death ${ }^{\mathrm{a}}$ & 3 & 0 & 1 & 1 & 5 & 29,938 \\
\hline $\begin{array}{l}\text { Congenital } \\
\text { malformation, any }\end{array}$ & 2 & 1 & 1 & 0 & 3 & 73,106 \\
\hline $\begin{array}{l}\text { Congenital } \\
\text { malformation, serious }\end{array}$ & 1 & 0 & 1 & 0 & 3 & 47,375 \\
\hline
\end{tabular}

${ }^{\text {a }}$ Gestational age $\geq 16$ weeks, stillborn or died during first seven days of life

${ }^{\mathrm{b}}$ As defined by the Medical Birth Registry of Norway

Table 2 Biochemical characteristics of 180 mothers with porphyria

\begin{tabular}{|c|c|c|c|c|}
\hline Diagnosis & Analyte (unit) & Upper reference limit & No. & $\begin{array}{l}\text { Median } \\
\text { (25-75 percentiles) }\end{array}$ \\
\hline \multirow[t]{2}{*}{ Latent acute porphyria ${ }^{a}$} & ALA $(\mu \mathrm{mol} / \mathrm{mmol}$ creatinine $)$ & $<5.0$ & 25 & $4.2(2.5-7.2)$ \\
\hline & PBG ( $\mu \mathrm{mol} / \mathrm{mmol}$ creatinine $)$ & $<0.8$ & 23 & $2.1(0.4-7.9)$ \\
\hline \multirow[t]{2}{*}{ Active acute porphyria $^{a}$} & ALA ( $\mu \mathrm{mol} / \mathrm{mmol}$ creatinine $)$ & $<5.0$ & 59 & $6.7(3.8-11.8)$ \\
\hline & PBG ( $\mu \mathrm{mol} / \mathrm{mmol}$ creatinine $)$ & $<0.8$ & 58 & $7.2(3.3-13.9)$ \\
\hline Erythropoietic protoporphyria & Free erythrocyte protoporphyrin ( $\mu \mathrm{mol} / \mathrm{L}$ erythrocytes) & $<1.9$ & 7 & $19.0(7.8-34.3)$ \\
\hline Sporadic porphyria cutanea tarda & Total urine porphyrins (nmol/mmol creatinine) & $<30$ & 37 & $1,028(686-1467)$ \\
\hline Familial porphyria cutanea tarda & Total urine porphyrins (nmol/mmol creatinine) & $<30$ & 44 & $825(463-1350)$ \\
\hline Unknown type porphyria cutanea tarda & Total urine porphyrins (nmol/mmol creatinine) & $<30$ & 8 & $1,068(600-2118)$ \\
\hline
\end{tabular}

$A L A$ delta aminolevulinic acid, $P B G$ porphobilinogen

${ }^{\text {a }}$ Acute intermittent porphyria, hereditary coproporphyria, or variegate porphyria 
Table 3 Risk of selected adverse outcomes in pregnancies of women with latent and active acute porphyria in comparison with the rest of the population (controls). Norway, 1967-2006

\begin{tabular}{|c|c|c|c|c|c|c|c|}
\hline \multirow[t]{2}{*}{ Outcome } & \multirow{2}{*}{$\begin{array}{l}\text { Controls } \\
(N=2,275,317) \\
\text { Per } 100 \text { deliveries }\end{array}$} & \multicolumn{3}{|c|}{ Latent acute porphyria $(N=62)$} & \multicolumn{3}{|c|}{ Active acute porphyria $(N=136)$} \\
\hline & & $\begin{array}{l}\text { Per } 100 \\
\text { deliveries }\end{array}$ & $\begin{array}{l}\text { OR crude } \\
(95 \% \mathrm{CI})\end{array}$ & $\begin{array}{l}\text { OR adjusted }^{\mathrm{a}} \\
(95 \% \mathrm{CI})\end{array}$ & $\begin{array}{l}\text { Per } 100 \\
\text { deliveries }\end{array}$ & $\begin{array}{l}\text { OR crude } \\
(95 \% \text { CI })\end{array}$ & $\begin{array}{l}\text { OR adjusted }^{\mathrm{a}} \\
(95 \% \mathrm{CI})\end{array}$ \\
\hline Preeclampsia and/or eclampsia & 2.9 & 0.0 & - & - & 2.2 & $0.8(0.2-3.3)$ & $0.8(0.2-3.6)$ \\
\hline Caesarean section & 9.1 & 4.8 & $0.5(0.2-1.5)$ & $0.5(0.2-1.6)$ & 5.1 & $0.5(0.2-1.5)$ & $0.6(0.2-1.7)$ \\
\hline Birth weight $<2,500 \mathrm{~g}$ & 4.2 & 1.6 & $0.4(0.1-2.7)$ & $0.4(0.1-2.8)$ & 2.9 & $0.7(0.3-1.9)$ & $0.7(0.3-1.9)$ \\
\hline Gestational age $<37$ weeks & 5.8 & 0.0 & - & - & 8.7 & $1.6(0.8-3.0)$ & $1.6(0.8-3.1)$ \\
\hline Small for gestational age ${ }^{\mathrm{b}}$ & 10.8 & 9.8 & $0.9(0.4-2.2)$ & $0.9(0.4-2.2)$ & 12.7 & $1.2(0.6-2.2)$ & $1.1(0.6-2.1)$ \\
\hline Perinatal death ${ }^{\mathrm{c}}$ & 1.4 & 0.0 & - & - & 3.2 & $2.3(0.9-6.3)$ & $2.3(0.8-6.1)$ \\
\hline Congenital malformation, any & 3.2 & 3.2 & $1.0(0.2-4.1)$ & $1.0(0.3-4.2)$ & 1.5 & $0.4(0.1-1.8)$ & $0.5(0.1-1.9)$ \\
\hline Congenital malformation, serious & 2.1 & 3.2 & $1.6(0.4-6.4)$ & $1.6(0.4-6.5)$ & 0.0 & - & - \\
\hline
\end{tabular}

$O R$ odds ratio, $C I$ confidence interval

a Adjusted for year of delivery (1967-1976, 1977-1986, 1987-1996, 1997-2006), maternal age (<25, 25-34, 35+ years) and birth order (nulliparous/ multiparous)

${ }^{\mathrm{b}}$ Effect measure relative risk (RR)

${ }^{\mathrm{c}}$ Gestational age $\geq 16$ weeks, stillborn or died during first 7 days of life

status, and body mass index (BMI) are not recorded, and smoking habits were only recorded from 1999 onward. Patients with acute porphyrias have to adhere to a healthy lifestyle to avoid inducing acute attacks. PCT, however, is precipitated by factors such as iron overload, hepatitis, alcohol use, and estrogens. Thus, lifestyle factors could be the cause of the association between PCT and adverse pregnancy outcomes.

In the largest study on porphyrias and pregnancy to date, the authors reviewed the obstetric histories of 50 women with active acute porphyria and their total of 129 pregnancies during the 1950s and 1960s (Brodie et al. 1977). They observed an $8 \%$ frequency of perinatal death, whereas in our study, a frequency of $3.2 \%$ was found. In our cohort, this represented an excess risk of perinatal death compared with the general population. As the study by Brodie et al. did not include a control group, their results cannot be directly compared with ours.

Published case reports on four pregnancies by three women with active AIP reported that all four infants were

Table 4 Risk of selected adverse outcomes in pregnancies of women with sporadic and familial porphyria cutanea tarda in comparison with the rest of the population (controls). Norway, 1967-2006

\begin{tabular}{|c|c|c|c|c|c|c|c|}
\hline \multirow[t]{2}{*}{ Outcome } & \multirow{2}{*}{$\begin{array}{l}\text { Controls } \\
(N=2,275,317) \\
\text { Per } 100 \text { deliveries }\end{array}$} & \multicolumn{3}{|c|}{ Sporadic porphyria cutanea tarda $(N=68)$} & \multicolumn{3}{|c|}{ Familial porphyria cutanea tarda $(N=95)$} \\
\hline & & $\begin{array}{l}\text { Per } 100 \\
\text { deliveries }\end{array}$ & $\begin{array}{l}\text { OR crude } \\
(95 \% \text { CI) }\end{array}$ & $\begin{array}{l}\text { OR adjusted }^{\mathrm{a}} \\
(95 \% \mathrm{CI})\end{array}$ & $\begin{array}{l}\text { Per } 100 \\
\text { deliveries }\end{array}$ & $\begin{array}{l}\text { OR crude } \\
(95 \% \mathrm{CI})\end{array}$ & $\begin{array}{l}\text { OR adjusted }^{\mathrm{a}} \\
(95 \% \text { CI })\end{array}$ \\
\hline Preeclampsia and/or eclampsia & 2.9 & 0.0 & - & - & 5.3 & $1.9(0.6-6.1)$ & $2.2(0.7-7.4)$ \\
\hline Caesarean section & 9.1 & 2.9 & $0.3(0.1-1.2)$ & $0.6(0.1-2.6)$ & 5.3 & $0.6(0.2-1.6)$ & $0.8(0.3-2.5)$ \\
\hline Birth weight $<2,500 \mathrm{~g}$ & 4.2 & 8.8 & $2.2(0.8-5.6)$ & $2.2(0.8-5.6)$ & 5.3 & $1.3(0.5-3.4)$ & $1.3(0.5-3.5)$ \\
\hline Gestational age $<37$ weeks & 5.8 & 9.7 & $1.7(0.8-3.8)$ & $1.8(0.8-4.1)$ & 5.7 & $1.0(0.4-2.6)$ & $1.0(0.4-2.8)$ \\
\hline Small for gestational age $\mathrm{b}^{\mathrm{b}}$ & 10.8 & 24.2 & $2.2(1.3-3.7)$ & $2.0(1.2-3.4)$ & 13.6 & $1.3(0.7-2.4)$ & $1.2(0.6-2.2)$ \\
\hline Perinatal death ${ }^{\mathrm{c}}$ & 1.4 & 1.6 & $1.1(0.2-8.1)$ & $0.9(0.1-6.7)$ & 4.5 & $3.4(1.3-8.5)$ & $3.0(1.2-7.7)$ \\
\hline Congenital malformation, any & 3.2 & 1.5 & $0.4(0.1-3.1)$ & $0.6(0.1-4.3)$ & 2.1 & $0.6(0.2-2.5)$ & $0.8(0.2-3.0)$ \\
\hline Congenital malformation, serious & 2.1 & 1.5 & $0.7(0.1-4.9)$ & $0.9(0.1-6.8)$ & 2.1 & $1.0(0.3-3.9)$ & $1.2(0.3-4.8)$ \\
\hline
\end{tabular}

$O R$ odds ratio, $C I$ confidence interval

${ }^{a}$ Adjusted for year of delivery (1967-1976, 1977-1986, 1987-1996, 1997-2006), maternal age (<25, 25-34, 35+ years), and birth order (nulliparous/ multiparous)

${ }^{\mathrm{b}}$ Effect measure relative risk (RR)

${ }^{\mathrm{c}}$ Gestational age $\geq 16$ weeks, stillborn or died during first seven days of life 
born SGA and one died shortly after delivery (Olund 1988; Wenger et al. 1998; Aggarwal et al. 2002). Others (Muralidhar et al. 2006) reported that of four pregnancies by a woman with VP, two infants were SGA and two died perinatally. Brodie et al. reported that babies born after an acute attack had occurred during pregnancy had lower birth weight than if no acute attack had occurred, but is not apparent whether this difference was due to in utero growth retardation or premature delivery. A publication bias toward pregnancies with adverse outcomes is to be expected in case reports. We did not observe an excess risk of SGA for mothers with active acute porphyria.

A review of six published case reports on PCT and pregnancy reported that all had "good perinatal outcomes", but two developed mild preeclampsia and one gestational diabetes (Loret de Mola et al. 1996). Based on this report, others have also suggested an association between PCT and preeclampsia (Aziz Ibrahim and Esen 2004). We cannot exclude nor confirm an association. The point estimates of excess risk suggested a twofold increased risk of preeclampsia in familial PCT, without reaching statistical significance, and no excess risk in sporadic PCT.

To our knowledge, no one has previously demonstrated an association between sporadic PCT and SGA infants, and for first-time mothers, a significant excess risk of low birth weight and premature delivery. More than $24 \%$ of singletons born by mothers with sporadic PCT had a weight below the tenth percentile for their actual gestational age, whereas no such excess risk was observed in familial PCT. Lifestyle-related factors such as alcohol use and hepatitis are, to a larger extent, associated with sporadic PCT than is familial PCT (Aarsand et al. 2009). At the time of diagnosis, $75 \%$ of women in the sporadic PCT group reported smoking daily or occasionally, whereas $22 \%$ in the familial PCT group did the same. Frequencies of inactive life style (less than $1 \mathrm{~h}$ physical activity per week) were $27 \%$ and $13 \%$ respectively. Smoking during pregnancy is a well known risk factor of low birth weight and SGA (Reeves and Bernstein 2008), and inactive lifestyle is associated with high BMI, which is a suggested risk factor of preterm delivery (Torloni et al. 2009). Therefore, a less healthy lifestyle among women with sporadic PCT than those with familial PCT might explain the observed differences in risk of low birth weight, preterm delivery, and SGA.

The opposite pattern was observed for perinatal death, of which mothers with familial PCT, but not with sporadic PCT, had an excess risk. PCT has been associated with diabetes (Bleasel and Varigos 2000), which is a known risk factor for perinatal death (Balsells et al. 2009). However, none of the women with PCT were registered with pregestational or gestational diabetes in the MBRN, although complicating factors such as diabetes are, in general, underreported to some extent (Engeland et al.
2009). A common or coinherited genetic cause of both familial PCT and perinatal death could be an explanation, even though the four women with familial PCT and perinatal loss all belonged to different families and harbored private mutations in the uroporphyrinogen decarboxylase gene.

An increased risk of perinatal death was also observed for mothers with active acute porphyria but not for mothers with latent disease. Active, symptomatic disease is characterized by increased plasma and urine levels of heme precursors during acute attacks, and as many as two thirds of patients with active AIP have increased levels also when in remission (Kauppinen and von und zu Fraunberg 2002). However, though less common, patients with latent disease can also present with increased urine and plasma levels. The exact mechanism by which the heme precursors cause acute symptoms is not fully understood, but neurotoxicity has been suggested (Pischik and Kauppinen 2009). Whether the precursors can cross the placental barrier and be harmful to the fetus, damage the placenta, or in some other way compromise the intrauterine environment, remains highly speculative. Alternatively, treatment of porphyric attacks might be harmful, even if several recently published case reports have suggested the use of heme arginate during pregnancy is safe (Marsden and Rees 2010; Badminton and Deybach 2006). Yet again, a common or coinherited genetic cause of active acute porphyria and perinatal loss might exist, even if the women had different mutations as the cause of their acute porphyria.

In conclusion, in this population-based cohort study, first-time mothers with active acute porphyria and mothers with familial PCT had excess risks of perinatal loss. Mothers with sporadic PCT had excess risks of SGA infants. The results must be interpreted with care and need to be confirmed by others. However, the findings suggest that women with porphyria should be monitored closely during pregnancy.

Funding The study was funded by The Norwegian Porphyria Centre (NAPOS). The authors confirm independence from the sponsor; the content of the article has not been influenced by the sponsor.

Open Access This article is distributed under the terms of the Creative Commons Attribution Noncommercial License which permits any noncommercial use, distribution, and reproduction in any medium, provided the original author(s) and source are credited.

\section{References}

Aarsand AK, Boman H, Sandberg S (2009) Familial and sporadic porphyria cutanea tarda: characterization and diagnostic strategies. Clin Chem 55:795-803 
Aggarwal N, Bagga R, Sawhney H, Suri V, Vasishta K (2002) Pregnancy with acute intermittent porphyria: a case report and review of literature. J Obstet Gynaecol Res 28:160-162

Andersson C, Innala E, Backstrom T (2003) Acute intermittent porphyria in women: clinical expression, use and experience of exogenous sex hormones. A population-based study in northern Sweden. J Intern Med 254:176-183

Aziz Ibrahim A, Esen UI (2004) Porphyria cutanea tarda in pregnancy: a case report. J Obstet Gynaecol 24:574-575

Badminton MN, Deybach JC (2006) Treatment of an acute attack of porphyria during pregnancy. Eur J Neurol 13:668-669

Baghestan E, Bordahl PE, Rasmussen SA, Sande AK, Lyslo I, Solvang I (2007) A validation of the diagnosis of obstetric sphincter tears in two Norwegian databases, the Medical Birth Registry and the Patient Administration System. Acta Obstet Gynecol Scand 86:205-209

Balsells M, Garcia-Patterson A, Gich I, Corcoy R (2009) Maternal and fetal outcome in women with type 2 versus type 1 diabetes mellitus: a systematic review and metaanalysis. J Clin Endocrinol Metab 94:4284-4291

Baxi LV, Rubeo TJ Jr, Katz B, Harber LC (1983) Porphyria cutanea tarda and pregnancy. Am J Obstet Gynecol 146:333-334

Bewley AP, Keefe M, White JE (1998) Erythropoietic protoporphyria improving during pregnancy. Br J Dermatol 139:145-147

Bleasel NR, Varigos GA (2000) Porphyria cutanea tarda. Australas J Dermatol 41:197-206

Brodie MJ, Moore MR, Thompson GG, Goldberg A, Low RA (1977) Pregnancy and the acute porphyrias. Br J Obstet Gynaecol $84: 726-731$

Cappell MS (2008) Hepatic disorders severely affected by pregnancy: medical and obstetric management. Med Clin North Am 92:739760

De Siervi A, Rossetti MV, Parera VE, Mendez M, Varela LS, del C Batlle AM (1999) Acute intermittent porphyria: biochemical and clinical analysis in the Argentinean population. Clin Chim Acta 288:63-71

Engeland A, Bjorge T, Daltveit AK, Vollset SE, Furu K (2009) Validation of disease registration in pregnant women in the Medical Birth Registry of Norway. Acta Obstet Gynecol Scand 88:1083-1089

Engelhardt K, Trinka E, Franz G et al (2004) Refractory status epilepticus due to acute hepatic porphyria in a pregnant woman: induced abortion as the sole therapeutic option? Eur J Neurol 11:693-697
Irgens LM (2000) The Medical Birth Registry of Norway. Epidemiological research and surveillance throughout 30 years. Acta Obstet Gynecol Scand 79:435-439

Jacquemyn Y (2003) Erythropoietic protoporphyria in pregnancy. J Obstet Gynaecol 23:196

Kanaan C, Veille JC, Lakin M (1989) Pregnancy and acute intermittent porphyria. Obstet Gynecol Surv 44:244-249

Kauppinen R, von und zu Fraunberg M (2002) Molecular and biochemical studies of acute intermittent porphyria in 196 patients and their families. Clin Chem 48:1891-900

Kubon C, Sivertsen A, Vindenes HA, Abyholm F, Wilcox A, Lie RT (2007) Completeness of registration of oral clefts in a medical birth registry: a population-based study. Acta Obstet Gynecol Scand 86:1453-1457

Loret de Mola JR, Muise KL, Duchon MA (1996) Porphyria cutanea tarda and pregnancy. Obstet Gynecol Surv 51:493-497

Madu AE, Whittaker SJ (2006) Erythropoietic protoporphyria in pregnancy. J Obstet Gynaecol 26:687-688

Marsden JT, Rees DC (2010) A retrospective analysis of outcome of pregnancy in patients with acute porphyria. J Inherit Metab Dis 33:591-596

Milo R, Neuman M, Klein C, Caspi E, Arlazoroff A (1989) Acute intermittent porphyria in pregnancy. Obstet Gynecol 73:450-452

Muralidhar A, Vikram RS, Pechtor K, Howells MR (2006) Recurrent variegate porphyria in a pregnant woman. J Obstet Gynaecol 26:809-810

Olund A (1988) Acute intermittent porphyria complicated by pregnancy. Clin Exp Obstet Gynecol 15:168-169

Pischik E, Kauppinen R (2009) Neurological manifestations of acute intermittent porphyria. Cell Mol Biol (Noisy-le-grand) 55:72-83

Puy H, Gouya L, Deybach JC (2010) Porphyrias. Lancet 375:924-937

Reeves S, Bernstein I (2008) Effects of maternal tobacco-smoke exposure on fetal growth and neonatal size. Expert Rev Obstet Gynecol 3:719-730

Skjaerven R, Bakketeig LS (1989) Classification of small-forgestational age births: weight-by-gestation standards of second birth conditional on the size of the first. Paediatr Perinat Epidemiol 3:432-447

Torloni MR, Betran AP, Daher S et al (2009) Maternal BMI and preterm birth: a systematic review of the literature with metaanalysis. J Matern Fetal Neonatal Med 22:1-14

Wenger S, Meisinger V, Brucke T, Deecke L (1998) Acute porphyric neuropathy during pregnancy-effect of haematin therapy. Eur Neurol 39:187-188 